\title{
Succesvolle behandeling van IgG4-gerelateerde retroperitoneale fibrose met rituximab
}

\author{
Lucas van Maaren · Tom Marcelissen · Marjan Slot · Tom Hermans
}

Geaccepteerd op: 9 juni 2021 / Published online: 2 juli 2021

(C) The Author(s) 2021

\begin{abstract}
Samenvatting Ontregelingen in het adaptieve en humorale immuunsysteem kunnen leiden tot IgG4-gerelateerde ziekte. Deze zeldzame ziekte kan zich manifesteren in verschillende organen, waaronder het retroperitoneum. Aldaar kan het aanleiding geven tot fibrose, met als voornaamste uitingen nierfunctiestoornissen door postrenale obstructie en/of pijnklachten. Naar aanleiding van twee casus beschrijven wij de klinische presentatie, diagnostiek en behandeling van dit ziektebeeld bij patiënten die na een eerdere behandeling met prednison succesvol werden behandeld met rituximab.
\end{abstract}

Trefwoorden prednison $\cdot$ flankpijn $\cdot$ FDG-PET-scan

\section{Successful treatment of IgG4 related} retroperitoneal fibrosis with rituximab

\begin{abstract}
Disbalances in the adaptive and humoral immune system may cause IgG4-related disease. This rare disease can affect multiple organ systems, including the retroperitoneum. Retroperitoneal fibrosis can result in postrenal obstruction with accompanied renal failure and/or pain. By means of two case presentations we want to draw attention to this rare disease entity and share our experiences regarding favorable treatment responses with rituximab after unsuccessful treatment with prednisolone.
\end{abstract}

Keywords prednisone · flank pain · FDG-PET scan

L. van Maaren · T. Marcelissen, PhD · T. Hermans, $\mathrm{PhD}(\bowtie)$ afdeling Urologie, MUMC+, Maastricht, Nederland tjnhermans@gmail.com

M. Slot, PhD

afdeling Immunologie, MUMC+, Maastricht, Nederland

\section{Introductie}

IgG4-gerelateerde ziekte kan zich manifesteren in een of meerdere organen, waarbij een door IgG4 gedreven ontstekingsreactie centraal lijkt te staan. Retroperitoneale fibrose (RPF) is een uitingsvorm van deze zeldzame ziekte-entiteit. Wij bespreken twee patiënten met IgG4-gerelateerde RPF die succesvol werden behandeld met rituximab.

\section{Casus 1}

De uroloog werd geconsulteerd bij een 68-jarige man die was opgenomen op de afdeling Interne Geneeskunde in verband met een acute nierinsufficiëntie (creatinine 1.256 micromol/l). De patiënt had geen urologische voorgeschiedenis, een normale urineproductie en, behoudens algehele malaise, geen specifieke klachten of LUTS. Poliklinisch was de patiënt reeds verwezen in verband met een unilaterale inflammatoire speekselklierzwelling en was er op een FDG-PET-scan sprake van FDG-accumulatie rondom de aorta en arteria iliaca beiderzijds. De patiënt gebruikte enkel amlodipine en was 23 jaar geleden gestopt met roken. Het laboratoriumonderzoek toonde een bezinking van $33 \mathrm{~mm} / \mathrm{u}$ en een CRP van $14 \mathrm{mg} / \mathrm{l}$. Het urinesediment was niet afwijkend. Er kon geen prerenale pathologie vastgesteld worden en een echografie van de nieren toonde rechts een normaal aspect van de cortex zonder hydronefrose en links het beeld van een schrompelnier. Omdat een renaal probleem werd vermoed, volgde een nierbiopt, die echter geen afwijkingen liet zien. Vervolgens werd een renogram verricht waarop een duidelijke opname van technetium in de rechternier te zien was, maar geen uitscheiding. Pro diagnosi werd vervolgens een nefrostomiecatheter (NSK) rechts geplaatst. Hiermee daalde het creatinine tot $141 \mathrm{micromol} / \mathrm{l}$, waarmee 


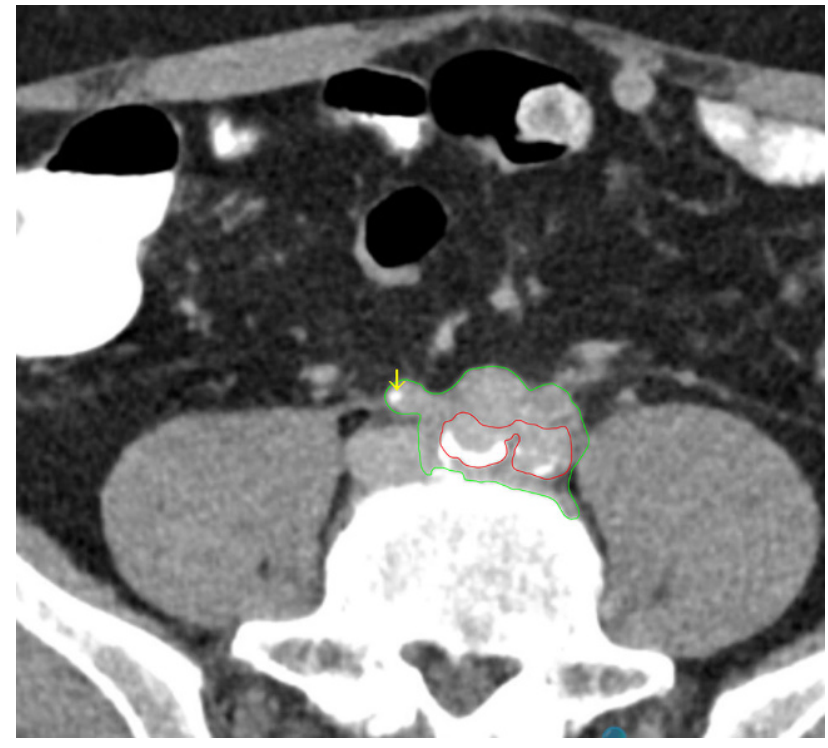

Figuur 1 Een transversale afbeelding van de CT-IVP van de patiënt in casus 1 . Hierop zijn de ureter (gele pijl), de aortabifurcatie (rood) en de retroperitoneale fibrose (groen) aangegeven

een postrenale oorzaak van het probleem evident werd. CT-IVP toonde, behoudens een beeld van RPF, geen aanwijzingen voor andere pathologie (fig. 1). Inmiddels waren in een speekselklierbiopt aanwijzingen gevonden voor IgG4-gerelateerde ziekte bij een serum-IgG4 van 3,88g/l (ref 0,08-1,40 g/l). Onder de werkdiagnose IgG4-gerelateerde ziekte met RPF werd een behandeling met prednison en cyclofosfamide gestart. Dit had na drie maanden onvoldoende effect. Bij een antegrade pyelo-ureterografie met een druk die werd opgebouwd tot $50 \mathrm{cmH}_{2} \mathrm{O}$ was er nog steeds geen passage van contrast naar de ureter en blaas. De behandeling werd gewijzigd en de patiënt ontving twee giften rituximab. Zes maanden nadien kon de NSK, ondanks het beeld van een proximale ureterstrictuur, alsnog succesvol verwijderd worden. Bij een druk van ongeveer $10 \mathrm{cmH}_{2} \mathrm{O}$ was er sprake van een vlotte passage van contrast tot in de blaas (fig. 2).

\section{Casus 2}

Een 60-jarige man presenteerde zich met acuut ontstane pijnklachten in het rechter hemi-abdomen en de flank. Ook in deze casus was er geen sprake van LUTS, hematurie of koorts. Behoudens een liesbreukherstel beiderzijds was er sprake van een blanco voorgeschiedenis. De patiënt rookte fors en werkte in een glaswol-verwerkingsbedrijf. Ondanks dat de patiënt een pijnlijke indruk maakte, was het abdominaal en genitaal onderzoek niet afwijkend. Het serumcreatinine was $91 \mathrm{micromol} / \mathrm{l}$ en de CRP $<6 \mathrm{mg} / \mathrm{l}$. Een CTIVP toonde een hydronefrose en een tortueus beloop van de proximale ureter tot net voorbij de kruising met de iliacale vaten. Aldaar bevond zich een subtiele periureterale massa (fig. 3). Het beeld was het meest suggestief voor een externe compressie van de ureter.

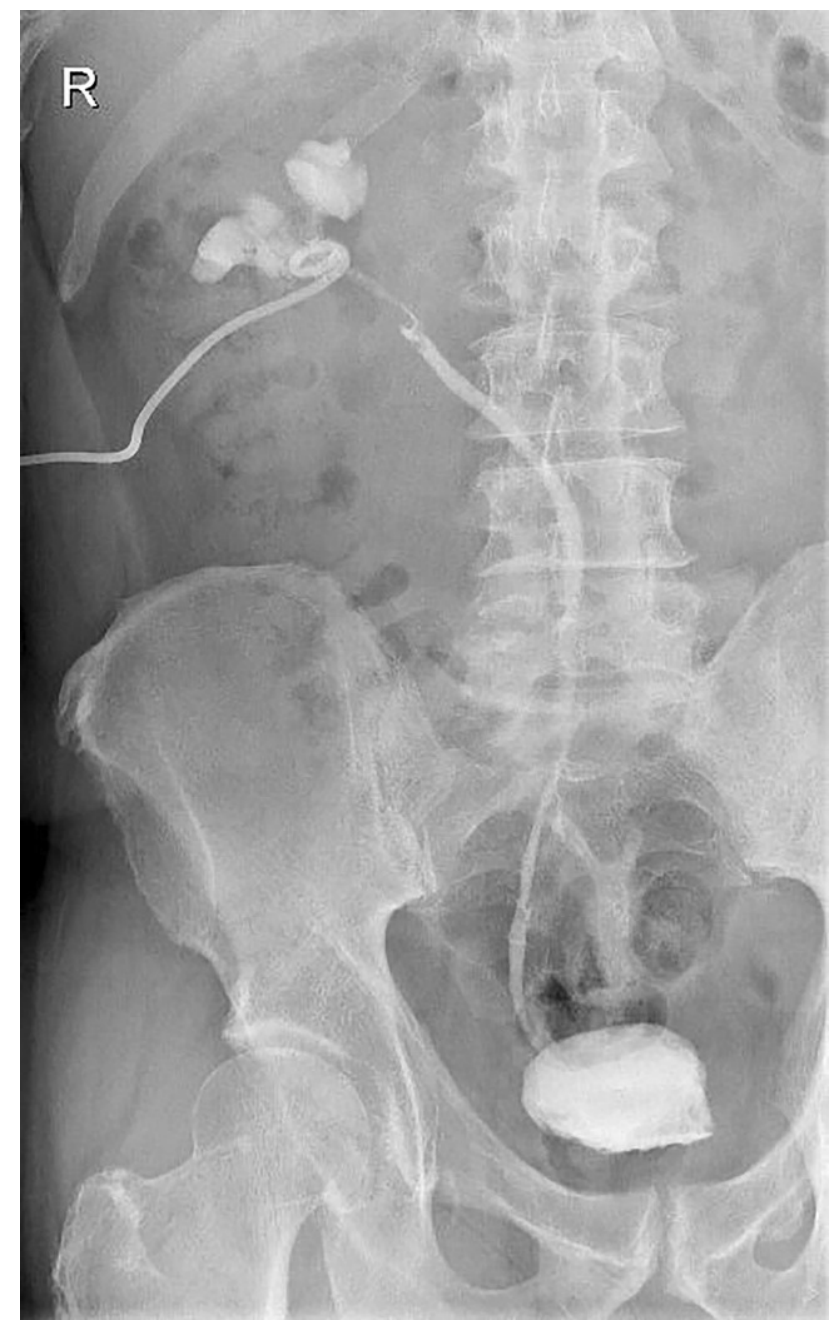

Figuur 2 Antegrade pyelo-ureterografie rechts van de patiënt in casus 1: ondanks het beeld van een proximale ureterstrictuur was er sprake van een vlotte passsage van contrast naar de blaas bij een druk van ongeveer $10 \mathrm{~cm} \mathrm{H}_{2} \mathrm{O}$

Gezien de pijnklachten en de hydronefrose werd er een NSK geplaatst. Vervolgens werd ook bij deze patiënt een FDG-PET-scan verricht. De eerder beschreven massa toonde een verhoogde FDG-accumulatie, en ook was er sprake van een verhoogde FDG-accumulatie in enkele prominente hilaire en mediastinale lymfeklieren. Een biopt van de periureterale massa werd na overleg met de interventieradioloog als te risicovol beschouwd. Het laboratoriumonderzoek toonde een bezinking van $23 \mathrm{~mm} / \mathrm{u}$ en een verhoogde IgG4waarde van 1,71 g/l (ref. 0,08-1,40 g/l). Een cytologische punctie van de mediastinale klieren toonde een lymfocytaire ontsteking. Gezien het klinisch beeld en de verhoogde IgG4-waarde werd de patiënt onder de werkdiagnose IgG4-gerelateerde ziekte behandeld met prednison en cellcept. De patiënt ontwikkelde daarbij een griepachtig beeld, waarop de cellcept gestaakt werd. Vervolgens ontving ook deze patiënt twee giften rituximab en werd de prednison afgebouwd. Een FDG-PET-scan toonde na enkele maanden een dui- 


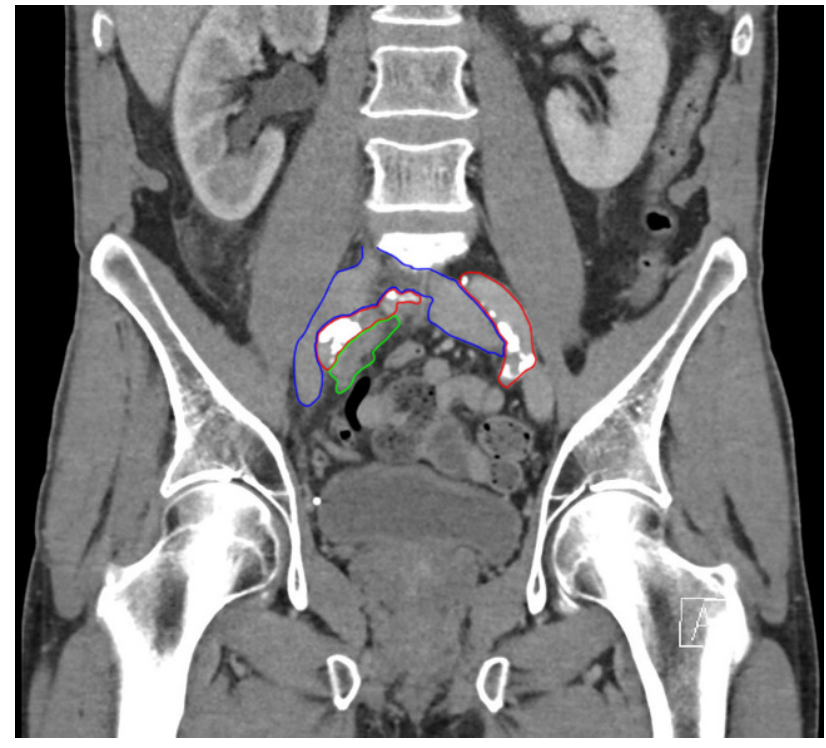

Figuur 3 Een coronale afbeelding van het CT-IVP van de patiënt in casus 2. Hierop zijn de venae iliaca (blauw), de arteriae iliaca (rood) en de retroperitoneale fibrose (groen) aangegeven

delijke afname van de periureterale massa waarbij de mediastinale lymfeklieren onveranderd aanwezig waren. Ook bij deze patiënt kon de NSK succesvol verwijderd worden.

\section{Discussie}

\section{Retroperitoneale fibrose}

Postrenale nierfunctiestoornissen worden veroorzaakt door een obstructie van de urinewegen en dienen in de acute fase veelal behandeld te worden middels drainage. Casus 1 illustreert dat er ook bij het ontbreken van een gedilateerd pyelocalicieel systeem toch sprake kan zijn van een obstructie van de urinewegen. De differentiaaldiagnose is breed, maar meestal is de diagnose snel duidelijk. In zeldzame gevallen is de oorzaak niet direct evident, en kan er op basis van anamnese, laboratoriumonderzoek en/of beeldvorming gedacht worden aan de diagnose RPF.

RPF omvat meerdere ziektebeelden die gekarakteriseerd worden door de aanwezigheid van fibro-inflammatoir weefsel. Dit weefsel bevindt zich meestal in het retroperitoneum rondom de abdominale aorta, de vena cava en de iliacale vaten. Door de fibrose kunnen de ureteren ter plaatse gecompromitteerd worden. Meestal is de oorzaak idiopathisch, maar de frequente associatie met auto-immuunziekten suggereert een manifestatie van een systemische inflammatoire auto-immuunziekte [1]. Verder wordt het ziektebeeld vaak gezien bij onderliggende problematiek van de aorta, inclusief de aanwezigheid van vaatprotheses. RPF is zeldzaam. Een Nederlandse studie berekende een jaarlijkse incidentie van 1,3 per 100.000 inwoners [2]. De patiënt is gemiddeld 40-60 jaar oud en de man-vrouwratio is ongeveer 2:1 [2, 3]. Bekende risicofactoren zijn roken en expositie aan asbest [4].

Het klachtenpatroon van RPF is vaak aspecifiek en daarom wordt de diagnose meestal pas gesteld als er sprake is van een significante nierfunctiestoornis door een obstructie van de ureteren. Pijn in de buik, onderrug en/of flank, met of zonder uitstraling richting de genitaalstreek is het meest gerapporteerde symptoom. De pijn kan fors zijn (VAS $4,9+/-2,7$ ) en gaat frequent gepaard met algemene symptomen, zoals malaise, anorexie, gewichtsverlies, koorts, misselijkheid en braken [1-3]. Vaak werken non-steroidal anti-inflammatory drugs (NSAID's) beter tegen de pijnklachten dan opiaten $[2,5]$. Uit laboratoriumonderzoek blijkt de serumcreatininewaarde frequent verhoogd. Bij het merendeel van de patiënten is er tevens sprake van een verhoogd CRP en BSE. Daarnaast wordt er frequent een normocytaire anemie gevonden $[2,5]$. Ook kan er sprake zijn van een verhoogd gehalte antinucleaire antistoffen (ANA) of antineutrofiele cytoplasmatische antistoffen (ANCA).

De medicamenteuze therapie van idiopathische RPF bestaat standaard uit prednison en/of - minder effectief - tamoxifen [3]. Deze behandeling gaat frequent gepaard met niet te miskennen bijwerkingen [3]. Indien onsuccesvol resteren enkel permanente drainages of grote reconstructieve chirurgische interventies (bijv. ureterolyse met omental 'wrapping' of een ileuminterpronaat).

\section{IgG4-gerelateerde ziekte en retroperitoneale fibrose}

In een recente serie van 113 RPF-patiënten bleek bij $21 \%$ van de deelnemers sprake van een verhoogd serum-immunoglobuline G4 (IgG4) [6]. Deze patiënten hadden frequenter extra-retroperitoneale fibro-inflammatoire laesies (casus 1), maar verder gelijkaardige ziektebeelden [5]. IgG4-gerelateerde ziekte heeft

\begin{tabular}{|l|l|l|l|l|l}
\hline Tabel 1 & \multicolumn{1}{|c}{ Uiting van IgG4-gerelateerde ziekte. Bron [8] } \\
\hline $\begin{array}{l}\text { orgaan } \\
\text { pancreas }\end{array}$ & \begin{tabular}{l} 
endo- en exocriene pancreasdisfunctie \\
\hline galboom, galblaas, lever \\
speeksel-, parotis- en traan- \\
klieren
\end{tabular} & $\begin{array}{l}\text { icterus, gewichtsverlies } \\
\text { zwelling aangedane klier, droogheid mond of } \\
\text { ogen }\end{array}$ \\
\hline retroperitoneum & $\begin{array}{l}\text { aspecifieke buikpijn, verlaagde } \\
\text { urineproductie }\end{array}$ \\
\hline nier & $\begin{array}{l}\text { verlaagde urineproductie, verhoogd creati- } \\
\text { nine waarde }\end{array}$ \\
\hline prostaat & LUTS \\
\hline Iongen & aspecifieke interstitiële pneumonie \\
\hline lymfatisch systeem & lymfeklierzwelling \\
\hline darmen, maag & colitis, gastro-enteritis \\
\hline zenuw, oog & zenuwuitval, uveïtis \\
\hline orbita & pseudotumor \\
\hline schildklier & kroep, schildkliernodus, disfunctie \\
\hline hypofyse & suppressie bijnieras \\
\hline grote vaten & aortitis, aneurysmata \\
\hline
\end{tabular}


de laatste jaren een plaats verworven als pathologisch concept [7]. Het klinisch spectrum is divers en bij deze ziekte kunnen meerdere orgaansystemen betrokken zijn (tab. 1; [8]). Die organen vertonen een aantal gemeenschappelijke kenmerken, zoals een tumorachtige zwelling, een lymfoplasmacytair infiltraat met IgG4-positieve plasmacellen en een variabele fibrogene component [8].

Bij beeldvorming is er geen specifiek patroon dat IgG4-gerelateerde ziekte kan onderscheiden van idiopathische RPF [10]. Voor het stellen van de diagnose wordt een biopt sterk aanbevolen [11].

Hoewel veel van de pathofysiologie van IgG4-gerelateerde ziekte nog onduidelijk is, lijkt er in ieder geval sprake van een ontregeling van zowel het aangeboren als het verworven immuunsysteem. Bij pathologisch onderzoek worden macrofagen en mestcellen gezien. Van beide is bekend dat ze een profibrotische stimulans geven. Daarnaast lijken diverse typen T-cellen een rol te spelen bij het onderhouden van de inflammatie en het aanzetten van B-cellen tot de productie van IgG4. Dit leidt uiteindelijk tot vorming van de IgG4-positieve plasmacellen, die ook veelvuldig aanwezig zijn in biopten. Mede gezien de overwegend goede therapierespons op rituximab bij patiënten met IgG4-gerelateerde ziekte lijkt de B-cel een centrale rol te vervullen in de inflammatie [12]. De binding van rituximab aan het CD20-antigeen op B-cellen activeert immunologische effectorfuncties, die resulteren in de celdood van B-cellen. De rol van IgG4 zelf is onduidelijk; proefdieronderzoek heeft wel laten zien dat injectie van IgG4 in muizen kan leiden tot een ontsteking van de speekselklier [9].

\section{Behandeling van IgG4-gerelateerde retroperitoneale fibrose}

De behandelstrategie bij IgG4-gerelateerde ziekte is vooralsnog onvoldoende gedefinieerd [13]. In een recente retrospectieve studie verminderden de pijnklachten bij alle 19 patiënten met IgG4-gerelateerde RPF die hiervoor een behandeling met rituximab zonder glucocorticoïden ontvingen. Bij $88 \%$ van de patiënten was er sprake van een radiologische verbetering. Bij vier van de 10 patiënten met een drain in de urinewegen kon deze drain succesvol verwijderd worden. Bij vier van de zes patiënten bij wie de drainage niet opgeheven kon worden, was er reeds sprake van een vastgestelde ziekteduur van minimaal één jaar. Het merendeel van de patiënten was nooit eerder met glucocorticosteroïden behandeld. Rituximab werd toegediend middels twee intraveneuze giften van $1000 \mathrm{mg}$ (week 0 en 2) en werd over het algemeen goed getolereerd [13]. Een belangrijke beperking van deze retrospectieve studie, in tegenstelling tot de door onze beschreven casuïstiek, betreft de korte followupduur van drie tot zes maanden. De auteurs suggereren het opzetten van een prospectieve studie waarbij een primaire behandeling met glucocorticosteroïden wordt afgezet tegen een primaire behandeling met rituximab bij patiënten met IgG4-gerelateerde RPF [13]. Helaas zijn er in de literatuur, behoudens enkele casuspresentaties, geen gegevens voorhanden over het langetermijneffect van een succesvolle initiële behandeling met rituximab bij IgG4-gerelateerde RPF [12].

De patiënten in casus 1 en 2 , die beiden werden verdacht van IgG4-gerelateerde RPF en die eerder waren behandeld met prednison, kregen twee giften rituximab. Na enkele maanden konden de NSK's succesvol verwijderd worden. Inmiddels, drie jaar later, zijn beide patiënten nog steeds klachtenvrij. Tot op heden was er geen noodzaak tot aanvullende behandelingen.

\section{Conclusie}

IgG4-gerelateerde retroperitoneale fibrose is een zeldzaam ziektebeeld. Indien een standaardbehandeling met prednison niet succesvol is, kan op basis van de beschreven casuïstiek en de beperkt beschikbare literatuur een behandeling met rituximab overwogen worden. Een dergelijke behandeling kan leiden tot remissie van ziekte, ervoor zorgen dat drainages van de urinewegen niet meer nodig zijn en kan reconstructieve ingrepen voorkomen.

Open Access This article is distributed under the terms of the Creative Commons Attribution 4.0 International License (http://creativecommons.org/licenses/by/4.0/), which permits unrestricted use, distribution, and reproduction in any medium, provided you give appropriate credit to the original author(s) and the source, provide a link to the Creative Commons license, and indicate if changes were made.

\section{Literatuur}

1. Vaglio A, Salvarani C, Buzio C. Retroperitoneal fibrosis. Lancet. 2006;367(9506):241-51.

2. Bommel EFH van, Jansen I, Hendriksz TR, Aarnoudse A. Idiopathic retroperitoneal fibrosis: prospective evaluation of incidence and clinicoradiologic presentation. Medicine (Baltimore). 2009;88(4):193-201.

3. Vaglio A, Palmisano A, Alberici F, et al. Prednisone versus tamoxifen in patients with idiopathic retroperitoneal fibrosis: an open-label randomised controlled trial. Lancet. 2011;378(9788):338-46.

4. Goldoni M, BoniniS, Urban ML, etal. Asbestos and smoking as risk factors for idiopathic retroperitoneal fibrosis: a casecontrol study. Ann Intern Med. 2014;161(3):181-8.

5. Scheel PJ Jr, Feeley N. Retroperitoneal fibrosis: the clinical, laboratory, and radiographic presentation. Medicine (Baltimore). 2009;88(4):202-7.

6. Maritati F, Rocco R, Accorsi ButtiniE, etal. Clinical and prognostic significance of serum IgG4 in chronic periaortitis. An analysis of 113 patients. Front Immunol. 2019;10:693.

7. Kamisawa T, Funata N, Hayashi Y, et al. A new clinicopathological entity of IgG4-related autoimmune disease. J Gastroenterol. 2003;38(10):982-4.

8. Maillette de Buy Wenniger LJ, Doorenspleet ME, Verheij J, Vries N de, Beuers U. IgG4-related disease. Ned Tijdschr Geneeskd. 2013;157(46):A6476. 
9. Liu C, Zhang P, Zhang W. Immunological mechanism of IgG4-related disease. JTransl Autoimmun. 2020;3:100047.

10. Forestier A, Buob D, Mirault T, et al. No specific imaging pattern can help differentiate IgG4-related disease from idiopathic retroperitoneal fibrosis: 18 histologically proven cases. Clin Exp Rheumatol. 2018;36(3):371-5.

11. Wallace ZS, Naden RP, Chari S, Choi HK, Della-Torre E, Dicaire JF, et al. The 2019 American College of Rheumatology/European League Against Rheumatism classification criteria for IgG4-related disease. Ann Rheum Dis. 2020;79(1):77-87.

12. Khosroshahi A, Carruthers MN, Deshpande V, Unizony S, Bloch DB, Stone JH. Rituximab for the treatment of IgG4- related disease: lessons from 10 consecutive patients. Medicine (Baltimore). 2012;91(1):57-66.

13. Wallwork R, Wallace Z, Perugino C. Rituximab for idiopathic and IgG4-related retroperitoneal fibrosis. Medicine (Baltimore). 2018;97(42):e12631.

Lucas van Maaren, coassistent urologie

Tom Marcelissen, uroloog

Marjan Slot, internist-immunoloog

Tom Hermans, aios urologie 


\title{
Hier staat een advertentie.
}

\author{
$c$ bohn

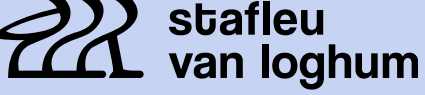 \\ Springer Media
}

Houten 2021 